rent is required to precipitate all of the copper and more attention must be paid to proper and rapid manipulation after precipitation. This method is much improved by previously precipitating the copper from its solution by boiling with aluminum foil and then redissolving the copper in nitric acid. The following results, obtained from the same sample, carefully prepared, obtained by the three methods, furnish a fair idea of the relative values of the several methods.

A copper matte, containing 20.15 per cent. of copper, as determined by a large number of analyses, nade by several different assayers, and by different methods, was run by each method. The amount of copper in the second matte, determined from the same data, was found to be twenty-eight per cent., while the per cent. of copper in the ore was 30.18 per cent.

The results obtained by the cyanide method were respectively 20. 5 per cent., 27.95 per cent., and 30.20 per cent. The copper was first precipitated with the aluminum foil. The same substances, with the iodide method, first precipitating with aluminum foil, gave, respectively, 20.25, 28.35, and 30.3 per cent. By the electrolytic method, the same substances gave, respectively, 20.045, 28. I5, and 30.05 per cent.

These results justify the statement that the iodide method with the aluminum modification gives results usually one-tenth to three-tenths per cent. too high, while the electrolytic method is too high or too low, according to the amount of metallic substances present precipitable by the electric current; and the cyanide method gives results which are practically correct.

\title{
ON THE STANDARDIZATION OF SULPHURIC ACID.
}

BY F. S. SHIVER.

Received February 16. 1895.

M WEINIG ${ }^{1}$ has described a method for the standardization of sulphuric acid by means of weighing the $\left(\mathrm{NH}_{4}\right)_{2} \mathrm{SO}_{4}$ obtained by mixing an accurately measured quantity of the sulphuric acid solution with an excess of ammonia, evaporating, drying, and weighing. His method of procedure is as follows: To an accurately measured quantity of the sulphuric acid solution, ammonia in slight excess is added, the solution evaporated to dryness, dried for half an hour at $115^{\circ}-$

$1 \mathrm{Ztschr}$, angew. Chem., $1892,204,205 ; \mathrm{J}$. Chem. Soc., 64, 2, 145. 
$120^{\circ} \mathrm{C}$, cooled in a desiccator, and weighed as ammonium sulphate $\left(\left(\mathrm{NH}_{4}\right)_{2} \mathrm{SO}_{4}\right)$. Recognizing the tendency of ammonium salts to decompose, especially when in aqueous solution and in the presence of heat, I was rather uncertain whether, by the mode of procedure just described, one would obtain the normal sulphate. Watts says concerning ammonium salts: "Their aqueous solution, when exposed to the air (still more rapidly when evaporated) generally loses ammonia, an acid salt or a normal salt mixed with excess of acid, being formed; hence, in crystallizing an ammonium salt, ammonia must be added occasionally during the evaporation." I therefore decided to make some experiments in this connection since it was of primary importance that the salt weighed should be the normal sulphate $\left(\left(\mathrm{NH}_{4}\right)_{2} \mathrm{SO}_{4}\right)$. Four portions of twenty ce. each of the $\underset{7}{\mathrm{~N}}$ sulphuric acid solution were accurately measured out and treated as directed by Weinig.

Results were as follows:

I. 0.3987 gram sulphur trioxide in twenty cc. of sulphuric acid. II. 0.3989 " " $\quad$ " " " $\quad$ " "

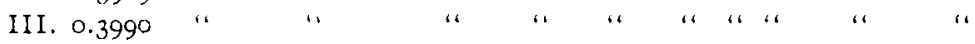
IV. 0.3992 " Aver. 0.3990 "

These residues tested with delicate litmus seemed to be feebly acid; to further test this point, four portions of twenty cc. each of this same acid were measured out and treated as follows: The acid solution was made alkaline with ammonia in excess and evaporated down to dryness; the dish was then removed from the bath and its contents thoroughly moistened with strong ammonia water, preferably $0.96 \mathrm{sp}$. gr. ; this will avoid the spattering occasioned by the use of concentrated ammonia water and is just as effective as the latter; the dish was then replaced on the bath and allowed to remain until its contents appeared quite dry, then removed and dried for half an hour at $110^{\circ}-120^{\circ} \mathrm{C}$, cooled in a desiccator, and weighed; the drying repeated for another half hour at the same temperature, cooled, and weighed; no further loss of weight occurred from this second drying in these experiments but I think it safer to weigh the second time, else one is left in doubt as to the thorough desiccation of the ammonium sulphate. The results by this method of treatment are as follows : 
I. 0.3996 gram sulphur trioxide in twenty cc. $\frac{N}{4}$ sulphuric acid.

II. 0.4001

III. 0.3993

IV. 0.3992

Average 0.3996 "

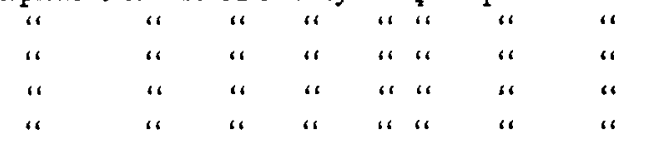

These residues tested with delicate litmus were neutral. It will be seen then that the results by the second mode of treatment are slightly higher in nearly all cases than those obtained by the first method described. In further proof of the slight decomposition that takes place when an aqueous solution of ammonium sulphate is evaporated to dryness, I took one of the residues obtained by the second method just described and added about as much water as there was present in the first evaporation; this solution was evaporated to dryness, dried as already described, cooled, and weighed; the weight of ammonium sulphate before adding water and second evaporation was $0.659 \mathrm{r}$ gram, after adding water and second evaporation $0.658 \mathrm{I}$ gram, a loss of 0.0010 gram ammonium sulphate; the amount of sulphui trioxide calculated from this weight of ammonium sulphate, viz., $0.65^{8} \mathrm{I}$ gram, will be seen to agree quite closely with the results secured by the first method described, in which there seems to be some slight decomposition of the ammonium sulphate.

Therefore from these experiments there seems to be some slight decomposition produced when an aqueous solution of ammonium sulphate is evaporated to dryness and in order to be sure to obtain the normal salt, it is necessary, in my experience, to moisten thoroughly with ammonia water the residue as has been described and then to dry and weigh in the manner directed. The decomposition noticed and the error in results occasioned by it is slight, though the results in most cases are lower than those obtained when precaution is taken to prevent this decomposition by moistening with ammonia water as has been described.

The results of this method compared with the precipitation by barium chloride and weighing as barium sulphate are quite close and satisfactory. In one cc. of $\frac{N}{4}$ sulphuric acid there was found by the barium chloride method 0.02007 gram sulphur trioxide equivalent to $0.00855 \mathrm{gram}$ ammonia. The ammonium sulphate 
method, as carried out by myself, gives 0.01998 gram sulphur trioxide equivalent to $0.0085 \mathrm{~g}$ gram ammonia. Therefore, one cc. of the sodium hydroxide solution $(50.35 \mathrm{cc}$. of which equals twenty cc. of the sulphuric acid) is equivalent to 0.003396 gram ammonia by the barium chloride method and by the ammonium sulphate method as carried out by myself 0.003380 gram ammonia.

Another solution of $\underset{f}{*}$ sulphuric acid was tested by the two methods.

In one cc. of the solution there was found by the barium chloride method 0.01977 gram sulplur trioxide equivalent to 0.00842 I gram ammonia.

The ammonium sulphate method, as carried out by myself, gives 0.019895 gram sulphur trioxide equivalent to 0.008474 gram ammonia. Therefore, one cc. of the sodium hyclroxide solution $\left(50.25 \mathrm{cc}\right.$. of which equals twenty $\mathrm{cc}$. of the $\mathrm{N}_{+}$sulphuric acid) is equivalent to 0.00335 I gram ammonia by the barium chloride method, and 0.003372 gram ammonia by the ammonium sulphate method, as carried out by myself. I think that as a method of standardization the annonium sulphate method will be found very simple and accurate and for these reasons should commend itself to those analysts who make use of sulphuric acid as their standard acid.

lebruary it, r895.

\section{ON SOME EXPERIMENTS IN THE ANTHRACENE SERIES.}

BY C. E. I.INEHARGER.

Received Mathith 4, 8995

T $\mathrm{O}$ anthracene is generally assigned the formula:

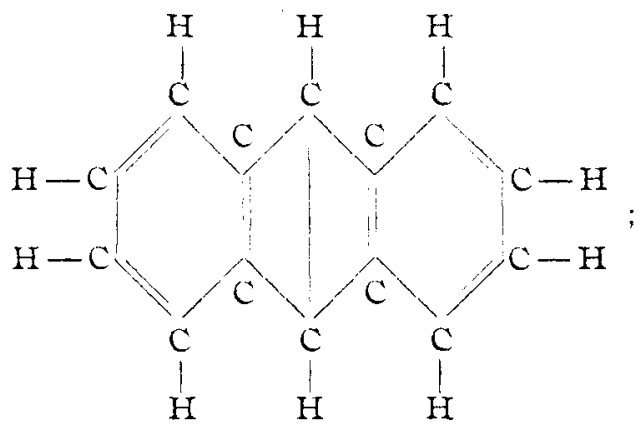

